\title{
National Institute on Alcohol Abuse and Alcoholism
}

National Cancer Institute

\section{Source}

National Cancer Institute. National Institute on Alcohol Abuse and Alcoholism. NCI

Thesaurus. Code C82603.

An institute within the National Institutes of Health that provides leadership in the national effort to reduce alcohol-related problems. 